\section{OPEN ACCESS}

Edited by:

Delphyne Descamps, INRA Centre Jouy-en-Josas, France

Reviewed by:

Prabakaran Ponraj, Sanofi Genzyme, United States

Randy A. Albrecht,

Icahn School of Medicine at Mount

Sinai, United States

*Correspondence:

Steve Bourgault

bourgault.steve@uqam.ca

Denis Archambault

archambault.denis@uqam.ca

Specialty section:

This article was submitted to Vaccines and Molecular Therapeutics,

a section of the journal

Frontiers in Immunology

Received: 06 November 2018 Accepted: 07 January 2019

Published: 24 January 2019

Citation:

Al-Halifa S, Gauthier L, Arpin D,

Bourgault $S$ and Archambault $D$ (2019) Nanoparticle-Based Vaccines

Against Respiratory Viruses.

Front. Immunol. 10:22.

doi: 10.3389/fimmu.2019.00022

\title{
Nanoparticle-Based Vaccines Against Respiratory Viruses
}

\author{
Soultan Al-Halifa ${ }^{1,2}$, Laurie Gauthier ${ }^{1,2,3,4}$, Dominic Arpin ${ }^{1,2,3,4}$, Steve Bourgault ${ }^{1,2,4 *}$ and \\ Denis Archambault ${ }^{3,4 *}$ \\ ${ }^{1}$ Département de Chimie, Université du Québec à Montréal, Montreal, QC, Canada, ${ }^{2}$ Quebec Network for Research on \\ Protein Function, Engineering and Applications, PROTEO, Quebec, QC, Canada, ${ }^{3}$ Département des Sciences Biologiques, \\ Université du Québec à Montréal, Montreal, QC, Canada, ${ }^{4}$ Faculté de Médecine Vétérinaire, Centre de Recherche en \\ Infectiologie Porcine et Avicole (CRIPA), Université de Montréal, St-Hyacinthe, QC, Canada
}

The respiratory mucosa is the primary portal of entry for numerous viruses such as the respiratory syncytial virus, the influenza virus and the parainfluenza virus. These pathogens initially infect the upper respiratory tract and then reach the lower respiratory tract, leading to diseases. Vaccination is an affordable way to control the pathogenicity of viruses and constitutes the strategy of choice to fight against infections, including those leading to pulmonary diseases. Conventional vaccines based on live-attenuated pathogens present a risk of reversion to pathogenic virulence while inactivated pathogen vaccines often lead to a weak immune response. Subunit vaccines were developed to overcome these issues. However, these vaccines may suffer from a limited immunogenicity and, in most cases, the protection induced is only partial. A new generation of vaccines based on nanoparticles has shown great potential to address most of the limitations of conventional and subunit vaccines. This is due to recent advances in chemical and biological engineering, which allow the design of nanoparticles with a precise control over the size, shape, functionality and surface properties, leading to enhanced antigen presentation and strong immunogenicity. This short review provides an overview of the advantages associated with the use of nanoparticles as vaccine delivery platforms to immunize against respiratory viruses and highlights relevant examples demonstrating their potential as safe, effective and affordable vaccines.

\section{Keywords: respiratory viruses, nanocarriers, nanovaccine, mucosal sites, immune response}

\section{INTRODUCTION}

Lower respiratory tract infections (LRTIs) constitute a major public health burden worldwide. LRTIs represent a leading cause of human mortality and morbidity, causing annually over 3 million deaths worldwide (1). Among these infections, about $80 \%$ of LRTI cases are caused by viruses (2). In most cases, these pathogens enter the host via airborne transmissions (e.g., droplets or aerosols), replicate efficiently in the respiratory tract and cause clinical manifestations, ranging from fever to bronchiolitis and pneumonia (3). In addition, LRTIs associated with viruses represent an important source of economic loss for livestock and poultry industry as these infections predispose animals to secondary bacterial infections (4-6).

Viruses infecting the human lower respiratory tract include the influenza virus, the respiratory syncytial virus (RSV), the parainfluenza virus and the adenovirus $(7,8)$. Seasonal influenza virus epidemics result in a significant burden of disease in children and elderlies and account for 3-5 
million cases of severe illness and for nearly 290,000-650,000 deaths worldwide each year (9). RSV and parainfluenza virus infections are the leading cause of hospitalization for acute respiratory infections in young children, causing 45 and $40 \%$ of pediatric hospitalizations, respectively $(10,11)$. Adenovirus infections account for $3-5 \%$ of LRTIs cases in children and can be fatal for immunocompromised patients (12). In general, respiratory viruses represent a major health problem in infants, young children, immunocompromised patients and the elderly population. According to Global Burden of Diseases (GBD), $74 \%$ of deaths associated with LRTIs represent these vulnerable patient groups (13).

Vaccination remains the most cost-effective strategy to fight against infectious diseases. Conventionally, vaccine formulations consist of attenuated viruses, killed pathogens (inactivated) or subunit protein antigens, which elicit a specific immune response. These vaccine formulations have allowed the prevention, or the control, of several important diseases including rubella, yellow fever, polio and measles, and, in the case of smallpox, even eradication $(14,15)$. Considerable efforts have been devoted for the development of efficient vaccines against LRTIs, including inactivated/fragmented trivalent or quadrivalent seasonal vaccines against influenza type A and type $B$ viruses such as Influvac ${ }^{\circledR}$ (16), Vaxigrip ${ }^{\circledR}$ (17), and Fluzone ${ }^{\circledR}(18)$ as well as live attenuated vaccines such as Nasovac ${ }^{\circledR}$ and Flumist ${ }^{\circledR}$ for nasal administration in young children $(19,20)$. Nevertheless, live-attenuated vaccines against influenza virus suffer from safety concerns due to their nature and represent a risk for elderly and immunosuppressed humans (21). Besides, killed pathogen vaccines and virus-derived subunit vaccines induce weaker immune responses and often require the use of an adjuvant to boost efficiency (22).

Several promising vaccines are currently evaluated in the clinics for different respiratory viruses (23). These new vaccine formulations aim to be safer and more efficient compared to traditional vaccines based on attenuated viruses, killed pathogens and subunits. Nevertheless, the high level of antigenic drift (genetic mutations) of some viruses, such as the influenza virus, reduces the efficacy of vaccines and needs to be addressed (24). Therefore, while improving safety and efficiency, vaccines should also be less sensitive to antigenic drift. The concept of "universal vaccine" is critical for viruses like the influenza virus, and new formulations to induce broad-spectrum immunity are being investigated. In the next sections, we discuss the advantages of using nanoparticle formulations against respiratory viruses and we highlight relevant examples of the use of nanoparticles as safe, effective, and affordable vaccines.

\section{NANOPARTICLES, AN ALTERNATIVE APPROACH TO CONVENTIONAL VACCINES}

The use of particles as nanoplatforms displaying relevant antigenic moieties is appealing as an alternative approach to conventional vaccines. These nano-sized materials can be obtained from biological sources and/or can be synthetic.
Currently, there is a large variety of particles evaluated as antigen carriers, including inorganic and polymeric nanoparticles, viruslike particles (VLPs), liposomes and self-assembled protein nanoparticles (Figure 1A). The advantages of these materials reside primarily in their size (at least one dimension should be at the nanometer level), since many biological systems such as viruses and proteins are nano-sized (25). Nanoparticles can be administered via sub-cutaneous and intramuscular injections, or can be delivered through the mucosal sites (oral and intranasal), and penetrate capillaries as well as mucosal surfaces $(26,27)$. Recent progresses have allowed the preparation of nanoparticles with unique physicochemical properties. For instance, size, shape, solubility, surface chemistry, and hydrophilicity can be tuned and controlled, which allows the preparation of nanoparticles with tailored biological properties (28). Moreover, nanoparticles can be designed to allow the incorporation of a wide range of molecules including antigens which makes them highly interesting in vaccinology $(29,30)$.

Incorporation of antigens in nanoparticles can be achieved by encapsulation (physical entrapment) or by conjugation (covalent functionalization) (21). Studies have demonstrated that nanoparticles could protect the native structure of antigens from proteolytic degradation and/or improve antigen delivery to antigen-presenting cells (APCs) (31). In addition, nanoparticles incorporating antigens can exert a local depot effect, ensuring prolonged antigen presentation to immune cells (32). Interestingly, nanoparticles have also shown intrinsic immunomodulatory activity (33). For instance, nanoparticles such as carbon nanotubes (CNTs), carbon black nanoparticles, poly(lactic-co-glycolic acid) (PLGA) and polystyrene nanoparticles, titanium dioxide $\left(\mathrm{TiO}_{2}\right)$ nanoparticles, silicon dioxide $\left(\mathrm{SiO}_{2}\right)$ nanoparticles, and aluminum oxyhydroxide nanoparticles have been reported to induce NLRP3-associated inflammasome activation (34). In fact, once internalized by APCs, these nanoparticles provide signals that trigger lysosomal destabilization and the production of reactive oxygen species (ROS), leading to the release of lysosomal contents, including the cysteine protease cathepsin B. This protease is sensed by NLRP3, which subsequently activates the formation of the inflammasome complex (35-39). Subsequently, interleukins are produced as downstream signaling events, leading to the recruitment and/or activation of immune cells $(35,40-45)$. Taken together, these properties advocate that nanoparticles are promising antigen carriers and immune cell activators for vaccination.

\section{NANOPARTICLES AND THE RESPIRATORY TRACT IMMUNE SYSTEM}

The respiratory mucosa represents the primary site for invasion and infection by a virus whose replication occurs in the ciliated cells of the upper respiratory tract (URT). Subsequently, infection spreads to the low respiratory tract (LRT) by virus-rich secretions and by infected cell debris from the URT (46). Nasal-associated lymphoid tissue (NALT), the first site for inhaled antigen recognition located in the URT, is an important line of defense 


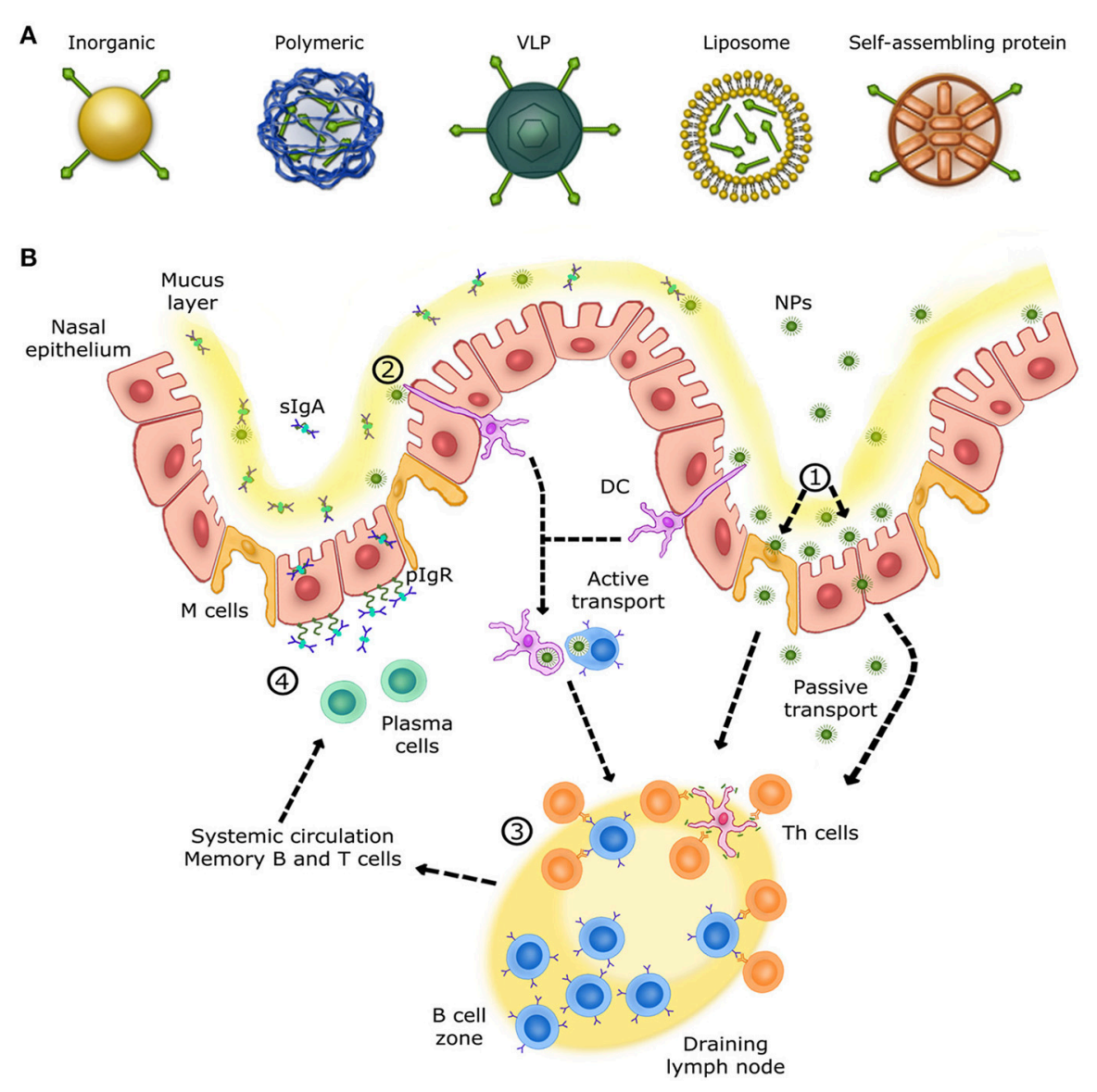

FIGURE 1 | Overview of the immune response in the upper respiratory tract. (A) Schematic view of different nanoparticles used for intranasal vaccination. (B) Mechanisms of NALTs immune responses in the upper respiratory tract. (1) Nanoparticles are transcytosed from the mucus layer into the nasal epithelial tissues by micro-fold cells (M cells) or passively diffuse through epithelial cell junctions. (2) Other nanoparticles are captured and internalized by DCs (dendritic cells) from their extension through epithelial junctions and by other APCs, such as B cells. (3) Cells that have encountered nanoparticles migrate to the nearest lymph node in order to activate naive T helper cells. Once activated, T helper cells activate B cells that have encountered the same antigen presented by nanoparticles. Activated B cells proliferate in the lymph node (B cell zone) and, once mature, enter systemic circulation in order to reach the inflammation site. IgA+ B cells locally differentiate into antibody-secreting plasma cells to produce IgA dimers. (4) IgA dimers are secreted via polymeric lg receptor (plgR) at the mucosal surface. NALT immune response induces long-lasting memory $B$ and $T$ cells able to trigger a rapid recall response.

against respiratory viruses. NALT is present in rodents, birds and primates (47). This structure is characterized by aggregates of lymphoid cells located in the nasopharyngeal cavity (48). In human, the Waldever's ring, made of adenoid and tonsil, is considered as the equivalent of NALT structure, which contains various narrow epithelial channels. NALT comprises aggregates of lymphoid follicles (B-cell areas), interfollicular areas (T-cell areas), macrophages and dendritic cells (DCs) (Figure 1B), which, when activated, support the clearance of infectious agents $(46,48,49)$. Accordingly, NALT is considered as an inductive site for humoral and cellular immune responses and represents a promising target for vaccines against respiratory viruses. Ideally, nanovaccines would follow a path similar to respiratory viruses in order to efficiently deliver antigens to NALT and trigger a specific mucosal immune response. Therefore, formulation, size and antigen exposition are critical aspects when designing nanovaccines targeting NALT. Most respiratory viruses have an average diameter size ranging between 20 and $200 \mathrm{~nm}$ (50-53).
Thus, in addition of being safe and immunogenic on its own, a nanovaccine should have a size similar to viruses while incorporating relevant antigens (54).

Over the last decade, a number of nanoparticles have been designed to mimic respiratory viruses in terms of size, shape and surface property in order to target NALT as well as to raise humoral and cellular immune responses $(21,55,56)$. First, beside a nanoparticle size of $20-200 \mathrm{~nm}$ in diameter to match the size of most respiratory viruses, nanoparticles should be preferably positively charged. In fact, positively charged polymeric, phospholipidic, metallic, inorganic, and proteinbased nanoparticles have shown stronger immune responses compared to their negatively charged counterparts $(21,57)$. Second, the incorporation of antigens/epitopes within or on the surface of the nanoparticles can be challenging and requires advanced approaches in chemical and/or biological engineering (21). The most common strategy is to encapsulate or entrap antigens/epitopes within the nanoparticles. In this case, 
nanoparticles are used to protect the antigen/epitopes and deliver them to NALT (58-60). Nanoencapsulation can be achieved by using different procedures, including nanoprecipitation and oil in water (o/w) emulsion (61). Alternatively, antigens can be attached and exposed on the nanoparticle surface. This strategy aims at mimicking viruses. Conjugation of antigenic epitope can be performed directly on the nanoparticles using different chemical reactions like the disulfide bond and the thiolate-gold bond formation (62-64). Otherwise, it can be achieved by first preparing an epitope-functionalized selfassembling unit, which upon self-assembly form nanoparticles decorated with the antigen (65-67). Third, the formulation and administration strategies are also critical aspects to consider. Vaccines administered via subcutaneous or intramuscular injection induce systemic immunity and usually, a weak mucosal response is observed. On the other hand, mucosal vaccination, either oral or intranasal delivery, induces humoral, and cellular immune responses at the systemic level and the mucosal surfaces, which is more effective in the protection against respiratory viruses $(68,69)$. Studies have demonstrated that vaccination via the intranasal route provides a better protection when compared to subcutaneous immunization in the context of respiratory pathogens and mucosal immunity. Intranasal vaccination led to higher antigen-specific lymphocyte proliferation, cytokine production (interferon- $\gamma$, interleukins) and induction of antigenspecific IgA antibody (70-74). A promising formulation strategy is the intranasal spray, which delivers conveniently and safely the nanovaccines directly to the respiratory mucosa (75-77). However, the number of clinical trials using nanovaccine formulations for intranasal delivery, including spray dried nanovaccines, is limited. This is mostly associated with the difficulty of keeping the nanovaccine integrity during the entire formulation process (76). Moreover, the immune response is particularly sensitive to the nature, size, shape, and surface properties of the nanoparticles as well as to the density and the potency of the antigens. Thus, it is very challenging to predict the effect of a given nanovaccine on the immune system. In addition, nanoparticles have some limitations associated with their synthesis, or preparation, and their properties. These include limited antigen loading, low synthesis yield, poor targeting capability to immune cells, limited manufacturability, and, in some cases, toxicity (78-80). These drawbacks can lead to side effects and/or poor immunogenicity, which precludes their clinical usage. Besides, little is known about the interactions between nanoparticles and immune cells. In fact, their adjuvant effect and their ability to activate the immune system still remain unclear and need to be better understood at the molecular level (81). Nonetheless, nanoparticle formulations have recently revealed promising results against respiratory virus infections (Table 1) and relevant examples will now be discussed.

\section{POLYMERIC NANOPARTICLES}

A polymer consists of a large molecule constructed from monomeric units. Depending on the construction, polymers can be linear, slightly branched or hyperbranched (3D network)
(104). Polymeric nanoparticles can be either obtained from the polymerization of monomeric units or from preformed polymers. These nanoparticles are attractive in the medical field due to their adjustable properties (size, composition, and surface properties), which allow controlled release, ability to combine both therapy and imaging (theranostics), and protection of drug molecules (105-107). For example, poly(lactic-co-glycolic acid) (PLGA) is a biodegradable and biocompatible polymer approved by the Food and Drug Administration (FDA) and European Medicines Agency (EMA) for use in humans. This is due to its ability to undergo hydrolysis in vivo, resulting in lactic acid and glycolic acid metabolites, which are efficiently processed by the body (108). PLGA can be engineered to form nanoparticles capable of encapsulating different types of biomolecules and release them sustainably over time (108-111). These nanoparticles can encapsulate antigens and prevent their degradation over 4 weeks under physiological conditions, which is critical for mucosal vaccination (112). Moreover, PLGANPs promote antigen internalization by APCs and facilitate antigen processing and presentation to naïve lymphocytes $(113,114)$. For instance, spherical PLGA-NPs $(200-300 \mathrm{~nm}$ of diameter) were used to encapsulate an inactivated Swine influenza virus (SwIV) H1N2 antigens (KAg) via water/oil/water double emulsion solvent evaporation (83). It was observed that pigs vaccinated twice with this preparation and challenged with a virulent heterologous influenza virus strain, have a significantly milder disease in comparison to non-vaccinated animals. This observation correlated closely with the reduced lung pathology and the substantial clearance of the virus from the animal lungs. Other polymeric nanoparticles, such as chitosan, a natural polymer composed of randomly distributed $\beta$-(1-4)-linked d-glucosamine and $\mathrm{N}$-acetyl-d-glucosamine, and $\mathrm{N}$-(2-hydroxypropyl)methacrylamide/ $\mathrm{N}$-isopropylacrylamide

(HPMA/NIPAM), were also investigated as intranasal vaccines against respiratory viruses $(85-90,115-121)$. Overall, polymeric nanoparticles have many advantages, including biocompatibility (122), antigen encapsulation and stabilization (123, 124), controlled release of antigens and intracellular persistence in APCs $(125,126)$, pathogen-like characteristics, and suitability for intranasal administration $(126,127)$. Nevertheless, the effect of the polymer properties (core chemistry, size, shape, surface properties) on the transport within the URT remains unknown. More studies are needed to better understand the effect of changing nanoparticle properties on their biological activities and to, ultimately, predict the fate of these nanocarriers upon their intranasal administration.

\section{SELF-ASSEMBLING PROTEIN NANOPARTICLES AND VLPS}

Self-assembling protein nanoparticles (SAPNs) are structures obtained from the oligomerization of monomeric proteins. The protein building blocks are mostly obtained through recombinant technologies and are considered safe for biomedical applications (128). SAPNs can be engineered to have a diameter ranging from 20 to $100 \mathrm{~nm}$, similar to the sizes of many 
TABLE 1 | Nanoparticle-based vaccines against respiratory viruses delivered via the intranasal route.

\begin{tabular}{|c|c|c|c|c|c|}
\hline Material & Size $(\mathrm{nm})$ & Virus & Antigen/Epitope & Adjuvant & References \\
\hline \multicolumn{6}{|c|}{ POLYMERIC NANOPARTICLES } \\
\hline \multirow[t]{2}{*}{ PLGA } & 225.4 & $\begin{array}{l}\text { Bovine parainfluenza } 3 \text { virus } \\
\text { (BPI3V) }\end{array}$ & BPI3V proteins & - & (82) \\
\hline & $200-300$ & Swine influenza virus (H1N2) & Inactivated virus $\mathrm{H} 1 \mathrm{~N} 2$ antigen & - & (83) \\
\hline$\gamma-\mathrm{PGA}^{\mathrm{a}}$ & 100-200 & Influenza (H1N1) & Hemagglutinin & - & (84) \\
\hline \multirow[t]{4}{*}{ Chitosan } & 140 & Influenza (H1N1) & H1N1 antigen & - & (85) \\
\hline & $300-350$ & Influenza (H1N1) & HA-Split & - & (86) \\
\hline & 571.7 & Swine influenza virus (H1N2) & Killed swine influenza antigen & - & (87) \\
\hline & $200-250$ & Influenza (H1N1) & $\mathrm{M} 2 \mathrm{e}$ & Heat shock protein 70c & (88) \\
\hline HPMA/NIPAM & $12-25$ & RSV & F protein & TLR-7/8 agonist & $(89,90)$ \\
\hline Polyanhydride & $200-800$ & RSV & F and G glycoproteins & - & $(91,92)$ \\
\hline \multicolumn{6}{|c|}{ SELF-ASSEMBLING PROTEINS AND PEPTIDE-BASED NANOPARTICLES } \\
\hline \multirow{3}{*}{$\begin{array}{l}\text { N nucleocapside } \\
\text { protein of RSV }\end{array}$} & 15 & RSV & RSV phosphoprotein & R192G & (93) \\
\hline & 15 & RSV & Fsll & Montanide $^{\mathrm{TM}}$ Gel 01 & $(94)$ \\
\hline & 15 & Influenza (H1N1) & $\mathrm{M} 2 \mathrm{e}$ & Montanide $^{\mathrm{TM}}$ Gel 01 & (95) \\
\hline Ferritin & 12.5 & Influenza (H1N1) & M2e & - & (96) \\
\hline Q11 & - & Influenza (H1N1) & Acid polymerase & - & $(97)$ \\
\hline \multicolumn{6}{|c|}{ INORGANIC NANOPARTICLES } \\
\hline Gold & 12 & Influenza & $\mathrm{M} 2 \mathrm{e}$ & CpG & $(64)$ \\
\hline \multicolumn{6}{|l|}{ OTHERS } \\
\hline \multirow[t]{3}{*}{ VLP } & $80-120$ & Influenza (H1N1) & Hemagglutinin & - & (98) \\
\hline & $80-120$ & Influenza (H1N1, H3N2, H5N1) & M2e & - & (99) \\
\hline & $80-120$ & RSV & $\begin{array}{l}\text { F protein et G glycoprotein of } \\
\text { RSV and M1 protein of Influenza }\end{array}$ & - & $(100)$ \\
\hline ISCOM $^{b}$ & 40 & Influenza (H1N1) & Hemagglutinin & ISCOMATRIX & $(101,102)$ \\
\hline DLPC liposomes ${ }^{C}$ & $30-100$ & Influenza (H1N1) & $\mathrm{M} 2, \mathrm{HA}, \mathrm{NP}$ & MPL and trehalose 6,6' dimycolate & (103) \\
\hline
\end{tabular}

apoly- $\gamma$-glutamic acid.

${ }^{b}$ Quillaia saponin, cholesterol, phospholipid, and associated antigen.

${ }^{c}$ Dilauroylphosphatidylcholine.

viruses and therefore, are considered as nanovaccine candidates against viruses, including respiratory viruses $(128,129)$. For example, SANPs, designed to elicit an immune response against RSV, have been explored using the nucleoprotein $(\mathrm{N})$ from the virus nucleocapsid. The $\mathrm{N}$ protein is a major target of antigen-specific cytotoxic T-cell response. The selfassembly of $\mathrm{N}$ protein protomers led to the formation of supramolecular nanorings of $15 \mathrm{~nm}$ diameter (93). This platform was modified by fusing the FsII epitope targeted by monoclonal neutralizing antibody (palivizumab) to the $\mathrm{N}$ protein, in order to form chimeric nanorings with enhanced immune response and virus protection against RSV. The results showed reduced virus load in the lungs of challenged mice (94). Similarly, chimeric nanorings displaying 3 repeats of the highly conserved ectodomain of the influenza virus A matrix protein 2 (M2e), were prepared by recombinant technologies (95). When administrated via the intranasal route, these M2efunctionalized nanorings induced local production of mucosal antibodies and led to mice protection (95). These $\mathrm{N}$-nanorings are interesting for intranasal delivery of antigen due to their similarities with respiratory viruses in term of size and structure (sub-nucleocapsid-like superstructures). Other examples of
SAPNs as potential nanovaccines against respiratory viruses include the capsid protein of the papaya mosaic virus (PapMV), the purified coronavirus spike protein and ferritin, which are selfassembling proteins that form rod-shaped and nearly spherical nanostructures, respectively $(96,130-140)$. Recently, assemblies composed of four tandem copies of M2e and headless HA proteins were prepared and stabilized by sulfosuccinimidyl propionate crosslinking, showing the possibility of generating protein nanoparticles almost entirely composed of the antigens of interest (141).

VLPs are spherical supramolecular assemblies of $20-200 \mathrm{~nm}$ diameter, which result from the self-assembly of viral capsid proteins. These particles are free from genetic materials and have the advantage of mimicking perfectly the structure and the antigenic epitopes of their corresponding native viruses. Therefore, this repetitive antigen display promotes efficient phagocytosis by APCs and subsequent activation (142-146). Recently, Lee and colleagues demonstrated that intranasal delivery of influenza-derived VLPs expressed in insect cells and exposing 5 repeats of the M2e epitopes, confers cross protection against different serotypes of influenza viruses by inducing humoral and cellular immune responses (99). 
SAPNs and VLPs are thus attractive but their formulation into stable and spray dried vaccines for intranasal injection can be challenging and may require the use of surfactants and saccharides (147). In the last decades, self-assembling peptides (SAPs) have also been investigated as intranasal nanovaccines against respiratory viruses due to their straightforward chemical synthesis and their storage stability upon lyophilization (97).

\section{INORGANIC NANOPARTICLES}

There are many inorganic nanoparticles suitable for biomedical applications, including superparamagnetic nanoparticles (iron oxide nanoparticles), quantum dots and plasmonic nanoparticles (gold and silver nanoparticles). Inorganic materials are mostly used as tools with improved therapeutic efficacy, biodistribution and pharmacokinetics. However, inherently, plain inorganic core nanoparticles would not be suitable in biological fluids due to particle aggregation. Therefore, in the medical field, these nanoparticles are often coated with organic molecules via adsorption or chemical reactions. In fact, these biocompatible nanoparticles can be described as complex hybrids materials with an inorganic core and an organic outer shell $(148,149)$. Among inorganic nanoparticles, the most commonly used for vaccination are gold nanoparticles (AuNPs). AuNPs are readily internalized by macrophages and dendritic cells, and induce their activation $(150,151)$. Large scale production is possible with strict control on particle size and ease of functionalization using the strong affinity between thiol groups and gold. Thiol groups can be attached to AuNP surface by forming thiolate-Au bonds (152-155). Furthermore, no immune response is elicited toward inert carriers like AuNPs (156). Thus, these nanoparticles are an appealing platform for nanovaccine engineering via antigen functionalization.

A wide range of molecules, including adjuvants and antigens can be conjugated on AuNPs at high density, resulting in improved immunogenicity and antigen presentation $(157,158)$. AuNPs can be formulated for intranasal administration and can diffuse into the lymph nodes, triggering robust antigenspecific cytotoxic T-cell immune responses $(159,160)$. Tao and coworkers have demonstrated that the peptide consensus M2e of influenza A viruses with a non-native cysteine residue at the C-terminal end could be attached on the AuNPs via thiolate$\mathrm{Au}$ chemistry. The resulting M2e-AuNPs was administered by the intranasal route to mice with $\mathrm{CpG}$ (cytosine-guanine rich oligonucleotide) adjuvant, triggering a fully protective immune response against the influenza virus PR8 strain (161). More recently, it was demonstrated that this formulation could induce lung $B$ cell activation and robust serum antiM2e IgG response, with stimulation of both IgG1 and IgG2a

\section{REFERENCES}

1. World Health Organization. Top 10 Global Causes of Deaths. Geneva: World Health Organization (2016).

2. Seo YB, Song JY, Choi MJ, Kim IS, Yang TU, Hong KW, et al. Etiology and clinical outcomes of acute respiratory virus infection in subclasses (161). Additionally, this vaccination strategy led to protection against infection by the pandemic influenza virus strain, A/California/04/2009 (H1N1pdm) pandemic strain, influenza virus A/Victoria/3/75 (H3N2) strain and the highly pathogenic avian influenza virus A/Vietnam/1203/2004 (H5N1) (64). Although gold nanoparticles constitute an attractive platform for antigen conjugation, they can accumulate in organs such as liver and spleen for a long period, which could be ultimately associated with toxicity (162). Coating with biocompatible materials reduces their toxicity, although it can lead to alterations of the physicochemical and biological properties. Therefore, safety issues of AuNPs still need to be addressed.

\section{CONCLUSION AND PERSPECTIVES}

Engineered nanoparticles have demonstrated their potential as vaccine delivery platforms. They can be envisaged as both antigen nanocarriers and adjuvants. In all cases, intranasal administration of nanovaccines allows a convenient and safe delivery of the antigen to NALT, inducing mucosal and systemic immunity. Nonetheless, additional studies are still needed before their clinical translation. While intranasal vaccination of nanoparticles generates specific IgA antibody in the URT and leads to high survival rates in animal models, there are still limited studies on non-human primates, thus making nanoparticle's fate difficult to predict in a human URT. In addition, nanoparticle vaccines are generally functionalized with specific antigen(s), which result in an immune response targeted against these antigenic determinants. Considering antigenic drifts, the growing human population that needs to be vaccinated and the different type of viruses, the cost to address all these aspects would be too prohibitive to produce affordable vaccines. Consequently, the development of broad spectrum vaccines constitutes a critical need and we consider that nanovaccine engineering will contribute to achieve this objective.

\section{AUTHOR CONTRIBUTIONS}

SA-H, LG, DoA, SB, and DeA have participated in writing and preparation of the manuscript, and approved it for publication.

\section{FUNDING}

This work was supported by grants from the Natural Sciences and Engineering Research Council of Canada (NSERC; RGPIN2016-06532 and RGPIN-2018-06209) and the International Development Research Center (IDRC; 108517) to DeA and SB. hospitalized adults. Infect Chemother. (2014) 46:67-76. doi: 10.3947/ic.2014. 46.2.67

3. Kutter JS, Spronken MI, Fraaij PL, Fouchier RA, Herfst S. Transmission routes of respiratory viruses among humans. Curr Opin Virol. (2018) 28:142-51. doi: 10.1016/j.coviro.2018. 01.001 
4. Griffin D. Economic impact associated with respiratory disease in beef cattle. Vet Clin North Am Food Anim Pract. (1997) 13:367-77. doi: 10.1016/S0749-0720(15)30302-9

5. Taylor JD, Fulton RW, Lehenbauer TW, Step DL, Confer AW. The epidemiology of bovine respiratory disease: what is the evidence for predisposing factors? Can Veterinary J. (2010) 51:1095-102.

6. Johnson KK, Pendell DL. Market impacts of reducing the prevalence of bovine respiratory disease in united states beef cattle feedlots. Front Vet Sci. (2017) 4:189. doi: 10.3389/fvets.2017.00189

7. Walker TA, Khurana S, Tilden SJ. Viral respiratory infections. Pediatr Clin North Am. (1994) 41:1365-81. doi: 10.1016/S0031-3955(16)38876-9

8. Pavia AT. Viral infections of the lower respiratory tract: old viruses, new viruses, and the role of diagnosis. Clin Infect Dis. (2011) 52 (Suppl. 4):S284-9. doi: $10.1093 / \mathrm{cid} / \mathrm{cir} 043$

9. World Health Organization. Influenza (Seasonal). World Health Organization (2018).

10. Branche AR, Falsey AR. Parainfluenza virus infection. Semin Respir Crit Care Med. (2016) 37:538-54. doi: 10.1055/s-0036-1584798

11. Mazur NI, Higgins D, Nunes MC, Melero JA, Langedijk AC, Horsley N, et al. The respiratory syncytial virus vaccine landscape: lessons from the graveyard and promising candidates. Lancet Infect Dis. (2018) 18:e295-e311. doi: 10.1016/S1473-3099(18)30292-5

12. Lu MP, Ma LY, Zheng Q, Dong LL, Chen ZM. Clinical characteristics of adenovirus associated lower respiratory tract infection in children. World $J$ Pediatr. (2013) 9:346-9. doi: 10.1007/s12519-013-0431-3

13. Collaborators GL. Estimates of the global, regional, and national morbidity, mortality, and aetiologies of lower respiratory tract infections in 195 countries: a systematic analysis for the Global burden of disease study 2015. Lancet Infect Dis. (2017) 17:1133-61. doi: 10.1016/S1473-3099(17) 30396-1

14. Fenner F, Henderson DA, Arita I, Jezek Z, Ladnyi ID. Smallpox and its Eradication. Geneva: World Health Organization (1988).

15. Hajj Hussein I, Chams N, Chams S, El Sayegh S, Badran R, Raad M, et al. Vaccines through centuries: major cornerstones of global health. Front Public Health (2015) 3:269. doi: 10.3389/fpubh.2015.00269

16. Daubeney P, Taylor CJ, Mcgaw J, Brown EM, Ghosal S, Keeton BR, et al. Immunogenicity and tolerability of a trivalent influenza subunit vaccine (Influvac) in high-risk children aged 6 months to 4 years. Br J Clin Pract. (1997) 51:87-90.

17. Delore V, Salamand C, Marsh G, Arnoux S, Pepin S, Saliou P. Long-term clinical trial safety experience with the inactivated split influenza vaccine, Vaxigrip. Vaccine (2006) 24:1586-92. doi: 10.1016/j.vaccine.2005.10.008

18. Grohskopf LA, Sokolow LZ, Olsen SJ, Bresee JS, Broder KR, Karron RA. Prevention and control of influenza with vaccines: recommendations of the advisory committee on immunization practices, United States, 2015-16 influenza season. Morb Mortal Wkly Rep. (2015) 64:818-25. doi: 10.15585/mmwr.mm6430a3

19. Carter NJ, Curran MP. Live attenuated influenza vaccine (FluMist(R); Fluenz): a review of its use in the prevention of seasonal influenza in children and adults. Drugs (2011) 71:1591-622. doi: 10.2165/11206860-000000000-00000

20. Dhere R, Yeolekar L, Kulkarni P, Menon R, Vaidya V, Ganguly M, et al. A pandemic influenza vaccine in India: from strain to sale within 12 months. Vaccine (2011) 29 (Suppl. 1):A16-21. doi: 10.1016/j.vaccine.2011.04.119

21. Chattopadhyay S, Chen JY, Chen HW, Hu CJ. Nanoparticle vaccines adopting virus-like features for enhanced immune potentiation. Nanotheranostics (2017) 1:244-60. doi: 10.7150/ntno.19796

22. Vartak A, Sucheck SJ. Recent advances in subunit vaccine carriers. Vaccines (2016) 4:12. doi: 10.3390/vaccines 4020012

23. Papadopoulos NG, Megremis S, Kitsioulis NA, Vangelatou O, West P, Xepapadaki P. Promising approaches for the treatment and prevention of viral respiratory illnesses. J Allergy Clin Immunol. (2017) 140:921-32. doi: 10.1016/j.jaci.2017.07.001

24. Boni MF. Vaccination and antigenic drift in influenza. Vaccine (2008) 26 (Suppl. 3):C8-14. doi: 10.1016/j.vaccine.2008.04.011

25. Laval JM, Mazeran PE, Thomas D. Nanobiotechnology and its role in the development of new analytical devices. Analyst (2000) 125:29-33. doi: $10.1039 / \mathrm{a} 907827 \mathrm{~d}$
26. Parveen K, Banse V, Ledwani L. Green synthesis of nanoparticles: their advantages and disadvantages. In: 5th National Conference on Thermophysical Properties: (Nctp-09). Rajasthan (2016). p. 1249.

27. Schneider CS, Xu Q, Boylan NJ, Chisholm J, Tang BC, Schuster BS, et al. Nanoparticles that do not adhere to mucus provide uniform and long-lasting drug delivery to airways following inhalation. Sci Adv. (2017) 3:e1601556. doi: $10.1126 /$ sciadv. 1601556

28. Angioletti-Uberti S. Theory, simulations and the design of functionalized nanoparticles for biomedical applications: a soft matter perspective. NPJ Comput Mater. (2017) 3:48. doi: 10.1038/s41524-017-0050-y

29. Irvine DJ, Hanson MC, Rakhra K, Tokatlian T. Synthetic nanoparticles for vaccines and immunotherapy. Chem Rev. (2015) 115:11109-46. doi: 10.1021/acs.chemrev.5b00109

30. Szeto GL, Lavik EB. Materials design at the interface of nanoparticles and innate immunity. $J$ Mater Chem $B$ (2016) 4:1610-8. doi: 10.1039/C5TB01825K

31. Pachioni-Vasconcelos Jde A, Lopes AM, Apolinario AC, Valenzuela-Oses JK, Costa JS, Nascimento Lde O, et al. Nanostructures for protein drug delivery. Biomater Sci. (2016) 4:205-18. doi: 10.1039/C5BM00360A

32. Fredriksen BN, Grip J. PLGA/PLA micro- and nanoparticle formulations serve as antigen depots and induce elevated humoral responses after immunization of Atlantic salmon (Salmo salar L.). Vaccine (2012) 30:656-67. doi: 10.1016/j.vaccine.2011.10.105

33. Mamo T, Poland GA. Nanovaccinology: the next generation of vaccines meets 21st century materials science and engineering. Vaccine (2012) 30:6609-11. doi: 10.1016/j.vaccine.2012.08.023

34. Zhu M, Wang R, Nie G. Applications of nanomaterials as vaccine adjuvants. Hum Vaccin Immunother. (2014) 10:2761-74. doi: 10.4161/hv.29589

35. Ghiringhelli F, Apetoh L, Tesniere A, Aymeric L, Ma Y, Ortiz C, et al. Activation of the NLRP3 inflammasome in dendritic cells induces IL-1 $\beta$ dependent adaptive immunity against tumors. Nat Med. (2009) 15:1170. doi: $10.1038 / \mathrm{nm} .2028$

36. Tschopp J, Schroder K. NLRP3 inflammasome activation: the convergence of multiple signalling pathways on ROS production? Nat Rev Immunol. (2010) 10:210. doi: $10.1038 /$ nri2725

37. Bruchard M, Mignot G, Derangère V, Chalmin F, Chevriaux A, Végran $\mathrm{F}$, et al. Chemotherapy-triggered cathepsin B release in myeloid-derived suppressor cells activates the Nlrp3 inflammasome and promotes tumor growth. Nat Med. (2012) 19:57. doi: 10.1038/nm.2999

38. Abderrazak A, Syrovets T, Couchie D, El Hadri K, Friguet B, Simmet T, et al. NLRP3 inflammasome: from a danger signal sensor to a regulatory node of oxidative stress and inflammatory diseases. Redox Biol. (2015) 4:296-307. doi: 10.1016/j.redox.2015.01.008

39. He Y, Hara H, Núñez G. Mechanism and regulation of NLRP3 inflammasome activation. Trends Biochem Sci. (2016) 41:1012-21. doi: 10.1016/j.tibs.2016.09.002

40. Cassel SL, Eisenbarth SC, Iyer SS, Sadler JJ, Colegio OR, Tephly LA, et al. The Nalp3 inflammasome is essential for the development of silicosis. Proc Natl Acad Sci USA (2008) 105:9035. doi: 10.1073/pnas.0803933105

41. Halle A, Hornung V, Petzold GC, Stewart CR, Monks BG, Reinheckel T, et al. The NALP3 inflammasome is involved in the innate immune response to amyloid- $\beta$. Nat Immunol. (2008) 9:857. doi: 10.1038/ni.1636

42. Sharp FA, Ruane D, Claass B, Creagh E, Harris J, Malyala P, et al. Uptake of particulate vaccine adjuvants by dendritic cells activates the NALP3 inflammasome. Proc Natl Acad Sci USA. (2009) 106:870-5. doi: $10.1073 /$ pnas.0804897106

43. Masters SL, Dunne A, Subramanian SL, Hull RL, Tannahill GM, Sharp FA, et al. Activation of the NLRP3 inflammasome by islet amyloid polypeptide provides a mechanism for enhanced IL-1 $\beta$ in type 2 diabetes. Nat Immunol. (2010) 11:897. doi: 10.1038/ni.1935

44. Niemi K, Teirila L, Lappalainen J, Rajamaki K, Baumann MH, Oorni K, et al. Serum amyloid A activates the NLRP3 inflammasome via P2X7 receptor and a cathepsin B-sensitive pathway. J Immunol. (2011) 186:6119-28. doi: 10.4049/jimmunol.1002843

45. Scharf B, Clement CC, Wu XX, Morozova K, Zanolini D, Follenzi $\mathrm{A}$, et al. Annexin A2 binds to endosomes following organelle destabilization by particulate wear debris. Nat Commun. (2012) 3:755. doi: $10.1038 /$ ncomms 1754 
46. Adair BM. Nanoparticle vaccines against respiratory viruses. Wiley Interdiscip Rev Nanomed Nanobiotechnol. (2009) 1:405-14. doi: 10.1002/wnan.45

47. Kang H, Yan M, Yu Q, Yang Q. Characteristics of nasal-associated lymphoid tissue (NALT) and nasal absorption capacity in chicken. PLoS ONE (2014) 8:e84097. doi: 10.1371/journal.pone.0084097

48. Marasini N, Skwarczynski M, Toth I. Intranasal delivery of nanoparticlebased vaccines. Ther Deliv. (2017) 8:151-67. doi: 10.4155/tde-2016-0068

49. Zuercher AW, Coffin SE, Thurnheer MC, Fundova P, Cebra JJ. Nasalassociated lymphoid tissue is a mucosal inductive site for virus-specific humoral and cellular immune responses. J Immunol. (2002) 168:1796. doi: 10.4049/jimmunol.168.4.1796

50. Lamb RA, Choppin PW. The gene structure and replication of influenza virus. Annu Rev Biochem. (1983) 52:467-506. doi: 10.1146/annurev.bi.52.070183.002343

51. Henrickson KJ. Parainfluenza viruses. Clin Microbiol Rev. (2003) 16:242-64. doi: 10.1128/CMR.16.2.242-264.2003

52. Utley TJ, Ducharme NA, Varthakavi V, Shepherd BE, Santangelo PJ, Lindquist ME, et al. Respiratory syncytial virus uses a Vps4-independent budding mechanism controlled by Rab11-FIP2. Proc Natl Acad Sci USA. (2008) 105:10209-14. doi: 10.1073/pnas.0712144105

53. Hall K, Blair Zajdel ME, Blair GE. Unity and diversity in the human adenoviruses: exploiting alternative entry pathways for gene therapy. Biochem J. (2010) 431:321-36. doi: 10.1042/BJ20100766

54. Gomes AC, Mohsen M, Bachmann MF. Harnessing nanoparticles for immunomodulation and vaccines. Vaccines (2017) 5:E6. doi: 10.3390/vaccines5010006

55. Niu Y, Yu M, Hartono SB, Yang J, Xu H, Zhang H, et al. Nanoparticles mimicking viral surface topography for enhanced cellular delivery. $A d v$ Mater. (2013) 25:6233-7. doi: 10.1002/adma.201302737

56. Fogarty JA, Swartz JR. The exciting potential of modular nanoparticles for rapid development of highly effective vaccines. Curr Opin Chem Eng. (2018) 19:1-8. doi: 10.1016/j.coche.2017.11.001

57. Fromen CA, Robbins GR, Shen TW, Kai MP, Ting JP, Desimone JM. Controlled analysis of nanoparticle charge on mucosal and systemic antibody responses following pulmonary immunization. Proc Natl Acad Sci USA. (2015) 112:488-93. doi: 10.1073/pnas.1422923112

58. Rahimian S, Kleinovink JW, Fransen MF, Mezzanotte L, Gold H, Wisse P, et al. Near-infrared labeled, ovalbumin loaded polymeric nanoparticles based on a hydrophilic polyester as model vaccine: In vivo tracking and evaluation of antigen-specific CD8(+) T cell immune response. Biomaterials (2015) 37:469-77. doi: 10.1016/j.biomaterials.2014.10.043

59. Kasturi SP, Kozlowski PA, Nakaya HI, Burger MC, Russo P, Pham M, et al. Adjuvanting a simian immunodeficiency virus vaccine with toll-like receptor ligands encapsulated in nanoparticles induces persistent antibody responses and enhanced protection in TRIM5alpha restrictive macaques. J Virol. (2017) 91:e01844-16. doi: 10.1128/JVI.01844-16

60. Kishimoto TK, Maldonado RA. Nanoparticles for the Induction of Antigen-Specific Immunological Tolerance. Front Immunol. (2018) 9:230. doi: 10.3389/fimmu.2018.00230

61. Kumari A, Singla R, Guliani A, Yadav SK. Nanoencapsulation for drug delivery. EXCLI J. (2014) 13:265-86.

62. Hirosue S, Kourtis IC, Van Der Vlies AJ, Hubbell JA, Swartz MA. Antigen delivery to dendritic cells by poly(propylene sulfide) nanoparticles with disulfide conjugated peptides: Cross-presentation and $\mathrm{T}$ cell activation. Vaccine (2010) 28:7897-906. doi: 10.1016/j.vaccine.2010.09.077

63. Ding P, Zhang T, Li Y, Teng M, Sun Y, Liu X, et al. Nanoparticle orientationally displayed antigen epitopes improve neutralizing antibody level in a model of porcine circovirus type 2. Int J Nanomed. (2017) 12:5239-54. doi: 10.2147/IJN.S140789

64. Tao W, Hurst BL, Shakya AK, Uddin MJ, Ingrole RS, Hernandez-Sanabria $\mathrm{M}$, et al. Consensus M2e peptide conjugated to gold nanoparticles confers protection against $\mathrm{H} 1 \mathrm{~N} 1, \mathrm{H} 3 \mathrm{~N} 2$ and $\mathrm{H} 5 \mathrm{~N} 1$ influenza A viruses. Antiviral Res. (2017) 141:62-72. doi: 10.1016/j.antiviral.2017.01.021

65. Mora-Solano C, Wen Y, Han H, Chen J, Chong AS, Miller ML, et al. Active immunotherapy for TNF-mediated inflammation using self-assembled peptide nanofibers. Biomaterials (2017) 149:1-11. doi: 10.1016/j.biomaterials.2017.09.031
66. Negahdaripour M, Golkar N, Hajighahramani N, Kianpour S, Nezafat $\mathrm{N}$, Ghasemi Y. Harnessing self-assembled peptide nanoparticles in epitope vaccine design. Biotechnol Adv. (2017) 35:575-96. doi: 10.1016/j.biotechadv.2017.05.002

67. Babych M, Bertheau-Mailhot G, Zottig X, Dion J, Gauthier L, Archambault $\mathrm{D}$, et al. Engineering and evaluation of amyloid assemblies as a nanovaccine against the Chikungunya virus. Nanoscale (2018) 10:19547-56. doi: 10.1039/C8NR05948A

68. Ichinohe T, Ainai A, Tashiro M, Sata T, Hasegawa H. PolyI:polyC12U adjuvant-combined intranasal vaccine protects mice against highly pathogenic H5N1 influenza virus variants. Vaccine (2009) 27:6276-9. doi: $10.1016 /$ j.vaccine.2009.04.074

69. Lycke N. Recent progress in mucosal vaccine development: potential and limitations. Nat Rev Immunol. (2012) 12:592-605. doi: 10.1038/nri3251

70. Chen L, Wang J, Zganiacz A, Xing Z. Single intranasal mucosal Mycobacterium bovis BCG vaccination confers improved protection compared to subcutaneous vaccination against pulmonary tuberculosis. Infect Immun. (2004) 72:238-46. doi: 10.1128/IAI.72.1.238-246.2004

71. Giri PK, Sable SB, Verma I, Khuller GK. Comparative evaluation of intranasal and subcutaneous route of immunization for development of mucosal vaccine against experimental tuberculosis. FEMS Immunol Med Microbiol. (2005) 45:87-93. doi: 10.1016/j.femsim.2005.02.009

72. Mapletoft JW, Latimer L, Babiuk LA, Van Drunen Littel-Van Den Hurk S. Intranasal immunization of mice with a bovine respiratory syncytial virus vaccine induces superior immunity and protection compared to those by subcutaneous delivery or combinations of intranasal and subcutaneous prime-boost strategies. Clin Vaccine Immunol. (2010) 17:23. doi: 10.1128/CVI.00250-09

73. Kharb S, Charan S. Mucosal immunization provides better protection than subcutaneous immunization against Pasteurella multocida (B:2) in mice preimmunized with the outer membrane proteins. Vet Res Commun. (2011) 35:457-61. doi: 10.1007/s11259-011-9484-8

74. Mccormick AA, Shakeel A, Yi C, Kaur H, Mansour AM, Bakshi CS. Intranasal administration of a two-dose adjuvanted multiantigen TMV-subunit conjugate vaccine fully protects mice against Francisella tularensis LVS challenge. PLoS ONE (2018) 13:e0194614. doi: 10.1371/journal.pone.0194614

75. Birkhoff $M$, Leitz M, Marx D. Advantages of intranasal vaccination and considerations on device selection. Indian J Pharmaceut Sci. (2009) 71:729-31.

76. Kanojia G, Have RT, Soema PC, Frijlink H, Amorij JP, Kersten G. Developments in the formulation and delivery of spray dried vaccines. Hum Vaccin Immunother. (2017) 13:2364-78. doi: 10.1080/21645515.2017.1356952

77. Kim SH, Jang YS. The development of mucosal vaccines for both mucosal and systemic immune induction and the roles played by adjuvants. Clin Exp Vaccine Res. (2017) 6:15-21. doi: 10.7774/cevr.2017.6.1.15

78. Shao K, Singha S, Clemente-Casares X, Tsai S, Yang Y, Santamaria P. Nanoparticle-based immunotherapy for cancer. ACS Nano. (2015) 9:16-30. doi: $10.1021 / \mathrm{nn} 5062029$

79. Zilker C, Kozlova D, Sokolova V, Yan H, Epple M, Überla K, et al. Nanoparticle-based B-cell targeting vaccines: tailoring of humoral immune responses by functionalization with different TLR-ligands. Nanomedicine (2017) 13:173-82. doi: 10.1016/j.nano.2016.08.028

80. Pan J, Wang Y, Zhang C, Wang X, Wang $\mathrm{H}$, Wang J, et al. Antigen-directed fabrication of a multifunctional nanovaccine with ultrahigh antigen loading efficiency for tumor photothermalimmunotherapy. Adv Mater. (2018) 30:1704408. doi: 10.1002/adma.2017 04408

81. Sahdev P, Ochyl LJ, Moon JJ. Biomaterials for nanoparticle vaccine delivery systems. Pharmaceut Res. (2014) 31:2563-82. doi: 10.1007/s11095-014-1419-y

82. Mansoor F, Earley B, Cassidy JP, Markey B, Doherty S, Welsh MD. Comparing the immune response to a novel intranasal nanoparticle PLGA vaccine and a commercial BPI3V vaccine in dairy calves. BMC Vet Res. (2015) 11:220. doi: 10.1186/s12917-015-0481-y

83. Dhakal S, Hiremath J, Bondra K, Lakshmanappa YS, Shyu DL, Ouyang $\mathrm{K}$, et al. Biodegradable nanoparticle delivery of inactivated swine influenza 
virus vaccine provides heterologous cell-mediated immune response in pigs. J Control Release (2017) 247:194-205. doi: 10.1016/j.jconrel.2016.12.039

84. Okamoto S, Matsuura M, Akagi T, Akashi M, Tanimoto T, Ishikawa $\mathrm{T}$, et al. Poly(gamma-glutamic acid) nano-particles combined with mucosal influenza virus hemagglutinin vaccine protects against influenza virus infection in mice. Vaccine (2009) 27:5896-905. doi: 10.1016/j.vaccine.2009.07.037

85. Liu Q, Zheng X, Zhang C, Shao X, Zhang X, Zhang Q, et al. Conjugating influenza a (H1N1) antigen to $n$-trimethylaminoethylmethacrylate chitosan nanoparticles improves the immunogenicity of the antigen after nasal administration. J Med Virol. (2015) 87:1807-15. doi: 10.1002/jmv. 24253

86. Sawaengsak C, Mori Y, Yamanishi K, Mitrevej A, Sinchaipanid N. Chitosan nanoparticle encapsulated hemagglutinin-split influenza virus mucosal vaccine. AAPS PharmSciTech. (2014) 15:317-25. doi: 10.1208/s12249-013-0058-7

87. Dhakal S, Renu S, Ghimire S, Shaan Lakshmanappa Y, Hogshead BT, Feliciano-Ruiz N, et al. Mucosal immunity and protective efficacy of intranasal inactivated influenza vaccine is improved by chitosan nanoparticle delivery in pigs. Front Immunol. (2018) 9:934. doi: 10.3389/fimmu.2018.00934

88. Dabaghian M, Latifi AM, Tebianian M, Najminejad H, Ebrahimi SM. Nasal vaccination with r4M2e.HSP70c antigen encapsulated into $\mathrm{N}$-trimethyl chitosan (TMC) nanoparticulate systems: preparation and immunogenicity in a mouse model. Vaccine (2018) 36:2886-95. doi: 10.1016/j.vaccine.2018.02.072

89. Lynn GM, Laga R, Darrah PA, Ishizuka AS, Balaci AJ, Dulcey AE, et al. In vivo characterization of the physicochemical properties of polymer-linked TLR agonists that enhance vaccine immunogenicity. Nat Biotechnol. (2015) 33:1201. doi: 10.1038/nbt.3371

90. Francica JR, Lynn GM, Laga R, Joyce MG, Ruckwardt TJ, Morabito $\mathrm{KM}$, et al. Thermoresponsive polymer nanoparticles Co-deliver RSV F Trimers with a TLR-7/8 Adjuvant. Bioconjug Chem. (2016) 27:2372-85. doi: 10.1021/acs.bioconjchem.6b00370

91. Ulery BD, Phanse Y, Sinha A, Wannemuehler MJ, Narasimhan B, Bellaire BH. Polymer chemistry influences monocytic uptake of polyanhydride nanospheres. Pharm Res. (2009) 26:683-90. doi: 10.1007/s11095-008-9760-7

92. Mcgill JL, Kelly SM, Kumar P, Speckhart S, Haughney SL, Henningson J, et al. Efficacy of mucosal polyanhydride nanovaccine against respiratory syncytial virus infection in the neonatal calf. Sci Rep. (2018) 8:3021. doi: 10.1038/s41598-018-21292-2

93. Roux X, Dubuquoy C, Durand G, Tran-Tolla TL, Castagne N, Bernard J, et al. Sub-nucleocapsid nanoparticles: a nasal vaccine against respiratory syncytial virus. PLoS ONE (2008) 3:e1766. doi: 10.1371/journal.pone.0001766

94. Herve PL, Deloizy C, Descamps D, Rameix-Welti MA, Fix J, Mclellan JS, et al. RSV N-nanorings fused to palivizumab-targeted neutralizing epitope as a nanoparticle RSV vaccine. Nanomedicine (2017) 13:411-20. doi: 10.1016/j.nano.2016.08.006

95. Herve PL, Raliou M, Bourdieu C, Dubuquoy C, Petit-Camurdan A, Bertho $\mathrm{N}$, et al. A novel subnucleocapsid nanoplatform for mucosal vaccination against influenza virus that targets the ectodomain of matrix protein 2 . J Virol. (2014) 88:325-38. doi: 10.1128/JVI.01141-13

96. Qi M, Zhang XE, Sun X, Zhang X, Yao Y, Liu S, et al. Intranasal nanovaccine confers homo- and hetero-subtypic influenza protection. Small (2018) 14:e1703207. doi: 10.1002/smll.201703207

97. Si Y, Wen Y, Kelly SH, Chong AS, Collier JH. Intranasal delivery of adjuvantfree peptide nanofibers elicits resident $\mathrm{CD} 8(+) \mathrm{T}$ cell responses. J Control Release (2018) 282:120-30. doi: 10.1016/j.jconrel.2018.04.031

98. Quan FS, Huang C, Compans RW, Kang SM. Virus-like particle vaccine induces protective immunity against homologous and heterologous strains of influenza virus. J Virol. (2007) 81:3514-24. doi: 10.1128/JVI.02052-06

99. Lee YT, Ko EJ, Lee Y, Kim KH, Kim MC, Lee YN, et al. Intranasal vaccination with M2e5x virus-like particles induces humoral and cellular immune responses conferring cross-protection against heterosubtypic influenza viruses. PLoS ONE (2018) 13:e0190868. doi: 10.1371/journal.pone. 0190868

100. Cai M, Wang C, Li Y, Gu H, Sun S, Duan Y, et al. Virus-like particle vaccine by intranasal vaccination elicits protective immunity against respiratory syncytial viral infection in mice. Acta Biochim Biophys Sin. (2017) 49:74-82. doi: 10.1093/abbs/gmw118

101. Wee JL, Scheerlinck JP, Snibson KJ, Edwards S, Pearse M, Quinn $\mathrm{C}$, et al. Pulmonary delivery of ISCOMATRIX influenza vaccine induces both systemic and mucosal immunity with antigen dose sparing. Mucosal Immunol. (2008) 1:489-96. doi: 10.1038/mi. 2008.59

102. Coulter A, Harris R, Davis R, Drane D, Cox J, Ryan D, et al. Intranasal vaccination with ISCOMATRIX $(\mathbb{R}$ adjuvanted influenza vaccine. Vaccine (2003) 21:946-9. doi: 10.1016/S0264-410X(02)00545-5

103. Tai W, Roberts L, Seryshev A, Gubatan JM, Bland CS, Zabriskie R, et al. Multistrain influenza protection induced by a nanoparticulate mucosal immunotherapeutic. Mucosal Immunol. (2011) 4:197-207. doi: $10.1038 / \mathrm{mi} .2010 .50$

104. Piluso S, Soultan AH, Patterson J. Molecularly engineered polymer-based systems in drug delivery and regenerative medicine. Curr Pharm Des. (2017) 23:281-94

105. Kamaly N, Xiao Z, Valencia PM, Radovic-Moreno AF, Farokhzad OC. Targeted polymeric therapeutic nanoparticles: design, development and clinical translation. Chem Soc Rev. (2012) 41:2971-3010. doi: $10.1039 / \mathrm{c} 2 \mathrm{cs} 15344 \mathrm{k}$

106. Krasia-Christoforou T, Georgiou TK. Polymeric theranostics: using polymerbased systems for simultaneous imaging and therapy. J Mater Chem B (2013) 1:3002. doi: 10.1039/c3tb20191k

107. Tang Z, He C, Tian H, Ding J, Hsiao BS, Chu B, et al. Polymeric nanostructured materials for biomedical applications. Progress Polymer Sci. (2016) 60:86-128. doi: 10.1016/j.progpolymsci.2016.05.005

108. Acharya S, Sahoo SK. PLGA nanoparticles containing various anticancer agents and tumour delivery by EPR effect. Adv Drug Deliv Rev. (2011) 63:170-83. doi: 10.1016/j.addr.2010.10.008

109. Mahapatro A, Singh DK. Biodegradable nanoparticles are excellent vehicle for site directed in-vivo delivery of drugs and vaccines. J Nanobiotechnol. (2011) 9:55. doi: 10.1186/1477-3155-9-55

110. Danhier F, Ansorena E, Silva JM, Coco R, Le Breton A, Preat V. PLGA-based nanoparticles: an overview of biomedical applications. J Control Release (2012) 161:505-22. doi: 10.1016/j.jconrel.2012.01.043

111. Silva AL, Soema PC, Slutter B, Ossendorp F, Jiskoot W. PLGA particulate delivery systems for subunit vaccines: linking particle properties to immunogenicity. Hum Vaccin Immunother. (2016) 12:1056-69. doi: 10.1080/21645515.2015.1117714

112. Getts DR, Shea LD, Miller SD, King NJ. Harnessing nanoparticles for immune modulation. Trends Immunol. (2015) 36:419-27. doi: 10.1016/j.it.2015.05.007

113. Woodrow KA, Bennett KM, Lo DD. Mucosal vaccine design and delivery. Annu Rev Biomed Eng. (2012) 14:17-46. doi: 10.1146/annurev-bioeng-071811-150054

114. Santos DM, Carneiro MW, De Moura TR, Soto M, Luz NF, Prates DB, et al. PLGA nanoparticles loaded with KMP-11 stimulate innate immunity and induce the killing of Leishmania. Nanomedicine (2013) 9:985-95. doi: 10.1016/j.nano.2013.04.003

115. Csaba N, Garcia-Fuentes M, Alonso MJ. Nanoparticles for nasal vaccination. Adv Drug Deliv Rev. (2009) 61:140-57. doi: 10.1016/j.addr.2008.09.005

116. Li P, Tan H, Xu D, Yin F, Cheng Y, Zhang X, et al. Effect and mechanisms of curdlan sulfate on inhibiting HBV infection and acting as an HB vaccine adjuvant. Carbohydr Polym. (2014) 110:446-55. doi: 10.1016/j.carbpol.2014.04.025

117. Li P, Zhang X, Cheng Y, Li J, Xiao Y, Zhang Q, et al. Preparation and in vitro immunomodulatory effect of curdlan sulfate. Carbohydr Polym. (2014) 102:852-61. doi: 10.1016/j.carbpol.2013.10.078

118. Islam S, Bhuiyan MAR, Islam MN. Chitin and chitosan: structure, properties and applications in biomedical engineering. J Polym Environ. (2016) 25:854-66. doi: 10.1007/s10924-016-0865-5

119. Marasini N, Giddam AK, Khalil ZG, Hussein WM, Capon RJ, Batzloff MR, et al. Double adjuvanting strategy for peptide-based vaccines: trimethyl chitosan nanoparticles for lipopeptide delivery. Nanomedicine (2016) 11:3223-35. doi: 10.2217/nnm-2016-0291

120. Wu M, Zhao H, Li M, Yue Y, Xiong S, Xu W. Intranasal vaccination with mannosylated chitosan formulated DNA vaccine enables robust IgA and 
cellular response induction in the lungs of mice and improves protection against pulmonary mycobacterial challenge. Front Cell Infect Microbiol. (2017) 7:445. doi: 10.3389/fcimb.2017.00445

121. Zhang S, Huang S, Lu L, Song X, Li P, Wang F. Curdlan sulfate-Olinked quaternized chitosan nanoparticles: potential adjuvants to improve the immunogenicity of exogenous antigens via intranasal vaccination. Int $J$ Nanomed. (2018) 13:2377-94. doi: 10.2147/IJN.S158536

122. Vela-Ramirez JE, Goodman JT, Boggiatto PM, Roychoudhury R, Pohl NL, Hostetter JM, et al. Safety and biocompatibility of carbohydratefunctionalized polyanhydride nanoparticles. AAPS J. (2015) 17:256-67. doi: 10.1208/s12248-014-9699-z

123. Carrillo-Conde B, Schiltz E, Yu J, Chris Minion F, Phillips GJ, Wannemuehler $\mathrm{MJ}$, et al. Encapsulation into amphiphilic polyanhydride microparticles stabilizes Yersinia pestis antigens. Acta Biomater. (2010) 6:3110-9. doi: 10.1016/j.actbio.2010.01.040

124. Petersen LK, Phanse Y, Ramer-Tait AE, Wannemuehler MJ, Narasimhan B. Amphiphilic polyanhydride nanoparticles stabilize Bacillus anthracis protective antigen. Mol Pharm. (2012) 9:874-82. doi: 10.1021/mp2004059

125. Ulery BD, Kumar D, Ramer-Tait AE, Metzger DW, Wannemuehler MJ, Narasimhan B. Design of a protective single-dose intranasal nanoparticlebased vaccine platform for respiratory infectious diseases. PLOS ONE (2011) 6:e17642. doi: 10.1371/journal.pone.0017642

126. Ulery BD, Petersen LK, Phanse Y, Kong CS, Broderick SR, Kumar D, et al. Rational design of pathogen-mimicking amphiphilic materials as nanoadjuvants. Sci Rep. (2011) 1:198. doi: 10.1038/srep00198

127. Ross KA, Haughney SL, Petersen LK, Boggiatto P, Wannemuehler MJ, Narasimhan B. Lung deposition and cellular uptake behavior of pathogenmimicking nanovaccines in the first 48 hours. Adv Healthc Mater. (2014) 3:1071-7. doi: 10.1002/adhm.201300525

128. Scheerlinck JP, Greenwood DL. Virus-sized vaccine delivery systems. Drug Discov Today (2008) 13:882-7. doi: 10.1016/j.drudis.2008.06.016

129. Schneider-Ohrum K, Ross TM. Virus-like particles for antigen delivery at mucosal surfaces. In: Kozlowski PA, editor. Mucosal Vaccines: Modern Concepts, Strategies, and Challenges. (Berlin;Heidelberg: Springer) (2012). pp. $53-73$.

130. Lawson DM, Artymiuk PJ, Yewdall SJ, Smith JM, Livingstone JC, Treffry $\mathrm{A}$, et al. Solving the structure of human $\mathrm{H}$ ferritin by genetically engineering intermolecular crystal contacts. Nature (1991) 349:541-4. doi: $10.1038 / 349541 \mathrm{a} 0$

131. Lee LA, Wang Q. Adaptations of nanoscale viruses and other protein cages for medical applications. Nanomedicine (2006) 2:137-49. doi: 10.1016/j.nano.2006.07.009

132. Li CQ, Soistman E, Carter DC. Ferritin nanoparticle technology. A new platform for antigen presentation and vaccine development. Ind Biotechnol. (2006) 2:143-7. doi: 10.1089/ind.2006.2.143

133. Yamashita I, Iwahori K, Kumagai S. Ferritin in the field of nanodevices. Biochim Biophys Acta (2010) 1800:846-57. doi: 10.1016/j.bbagen.2010.03.005

134. Yang S, Wang T, Bohon J, Gagne ME, Bolduc M, Leclerc D, et al. Crystal structure of the coat protein of the flexible filamentous papaya mosaic virus. J Mol Biol. (2012) 422:263-73. doi: 10.1016/j.jmb.2012.05.032

135. Babin C, Majeau N, Leclerc D. Engineering of papaya mosaic virus (PapMV) nanoparticles with a CTL epitope derived from influenza NP. J Nanobiotechnol. (2013) 11:10. doi: 10.1186/1477-3155-11-10

136. Kanekiyo M, Wei CJ, Yassine HM, Mctamney PM, Boyington JC, Whittle JR, et al. Self-assembling influenza nanoparticle vaccines elicit broadly neutralizing H1N1 antibodies. Nature (2013) 499:102-6. doi: $10.1038 /$ nature 12202

137. Coleman CM, Liu YV, Mu H, Taylor JK, Massare M, Flyer DC, et al. Purified coronavirus spike protein nanoparticles induce coronavirus neutralizing antibodies in mice. Vaccine (2014) 32:3169-74. doi: 10.1016/j.vaccine.2014.04.016

138. Lopez-Sagaseta J, Malito E, Rappuoli R, Bottomley MJ. Self-assembling protein nanoparticles in the design of vaccines. Comput Struct Biotechnol J. (2016) 14:58-68. doi: 10.1016/j.csbj.2015.11.001

139. Park H-J, Lee E-Y, Jung S, Ko HL, Lee S-M, Nam J-H. Spike nanoparticle and recombinant adenovirus 5 vaccines induce specific antibodies against the Middle East respiratory syndrome coronavirus (MERS-CoV). J Immunol. (2017) 198:225.
140. Therien A, Bedard M, Carignan D, Rioux G, Gauthier-Landry L, LaliberteGagne ME, et al. A versatile papaya mosaic virus (PapMV) vaccine platform based on sortase-mediated antigen coupling. J Nanobiotechnol. (2017) 15:54. doi: 10.1186/s12951-017-0289-y

141. Deng L, Mohan T, Chang TZ, Gonzalez GX, Wang Y, Kwon YM, et al. Double-layered protein nanoparticles induce broad protection against divergent influenza A viruses. Nat Commun. (2018) 9:359. doi: 10.1038/s41467-017-02725-4

142. Kushnir N, Streatfield SJ, Yusibov V. Virus-like particles as a highly efficient vaccine platform: diversity of targets and production systems and advances in clinical development. Vaccine (2012) 31:58-83. doi: 10.1016/j.vaccine.2012.10.083

143. Mathieu C, Rioux G, Dumas MC, Leclerc D. Induction of innate immunity in lungs with virus-like nanoparticles leads to protection against influenza and Streptococcus pneumoniae challenge. Nanomedicine (2013) 9:839-48. doi: 10.1016/j.nano.2013.02.009

144. Zeltins A. Construction and characterization of virus-like particles: a review. Mol Biotechnol. (2013) 53:92-107. doi: 10.1007/s12033-0129598-4

145. Zhao Q, Li S, Yu H, Xia N, Modis Y. Virus-like particle-based human vaccines: quality assessment based on structural and functional properties. Trends Biotechnol. (2013) 31:654-63. doi: 10.1016/j.tibtech.2013.09.002

146. Mohsen MO, Zha L, Cabral-Miranda G, Bachmann MF. Major findings and recent advances in virus-like particle (VLP)-based vaccines. Semin Immunol. (2017) 34:123-32. doi: 10.1016/j.smim.2017.08.014

147. Lang R, Winter G, Vogt L, Zurcher A, Dorigo B, Schimmele B. Rational design of a stable, freeze-dried virus-like particle-based vaccine formulation. Drug Dev Ind Pharm. (2009) 35:83-97. doi: 10.1080/03639040802192806

148. Feliu N, Docter D, Heine M, Del Pino P, Ashraf S, Kolosnjaj-Tabi J, et al. In vivo degeneration and the fate of inorganic nanoparticles. Chem Soc Rev. (2016) 45:2440-57. doi: 10.1039/C5CS00699F

149. Giner-Casares JJ, Henriksen-Lacey M, Coronado-Puchau M, LizMarzán LM. Inorganic nanoparticles for biomedicine: where materials scientists meet medical research. Mater Today (2016) 19:19-28.

150. Bastus NG, Sanchez-Tillo E, Pujals S, Farrera C, Kogan MJ, Giralt E, et al. Peptides conjugated to gold nanoparticles induce macrophage activation. Mol Immunol. (2009) 46:743-8. doi: 10.1016/j.molimm.2008.08.277

151. Kang S, Ahn S, Lee J, Kim JY, Choi M, Gujrati V, et al. Effects of gold nanoparticle-based vaccine size on lymph node delivery and cytotoxic T-lymphocyte responses. J Control Release (2017) 256:56-67. doi: 10.1016/j.jconrel.2017.04.024

152. Hiramatsu H, Osterloh FE. A simple large-scale synthesis of nearly monodisperse gold and silver nanoparticles with adjustable sizes and with exchangeable surfactants. Chem Mater. (2004) 16:2509-11. doi: $10.1021 / \mathrm{cm} 049532 \mathrm{v}$

153. Pensa E, Cortes E, Corthey G, Carro P, Vericat C, Fonticelli MH, et al. The chemistry of the sulfur-gold interface: in search of a unified model. Acc Chem Res. (2012) 45:1183-92. doi: 10.1021/ar20 0260p

154. Spampinato V, Parracino MA, La Spina R, Rossi F, Ceccone G. Surface analysis of gold nanoparticles functionalized with thiol-modified glucose SAMs for biosensor applications. Front Chem. (2016) 4:8. doi: 10.3389/fchem.2016.00008

155. Belmouaddine H, Shi M, Sanche L, Houde D. Tuning the size of gold nanoparticles produced by multiple filamentation of femtosecond laser pulses in aqueous solutions. Phys Chem Chem Phys. (2018) 20:23403-13. doi: 10.1039/C8CP02054J

156. Wang C, Zhu W, Luo Y, Wang BZ. Gold nanoparticles conjugating recombinant influenza hemagglutinin trimers and flagellin enhanced mucosal cellular immunity. Nanomedicine (2018) 14:1349-60. doi: 10.1016/j.nano.2018.03.007

157. Cao-Milan R, Liz-Marzan LM. Gold nanoparticle conjugates: recent advances toward clinical applications. Expert Opin Drug Deliv. (2014) 11:741-52. doi: 10.1517/17425247.2014.891582

158. Jazayeri MH, Amani $\mathrm{H}$, Pourfatollah AA, Pazoki-Toroudi $\mathrm{H}$, Sedighimoghaddam B. Various methods of gold nanoparticles (GNPs) conjugation to antibodies. Sens Bio Sensing Res. (2016) 9:17-22. doi: $10.1016 /$ j.sbsr.2016.04.002 
159. Salazar-Gonzalez JA, Gonzalez-Ortega O, Rosales-Mendoza S. Gold nanoparticles and vaccine development. Exp Rev Vaccines (2015) 14:1197-211. doi: 10.1586/14760584.2015.1064772

160. Marques Neto LM, Kipnis A, Junqueira-Kipnis AP. Role of metallic nanoparticles in vaccinology: implications for infectious disease vaccine development. Front Immunol. (2017) 8:239. doi: 10.3389/fimmu.2017.00239

161. Tao W, Ziemer KS, Gill HS. Gold nanoparticle-M2e conjugate coformulated with CpG induces protective immunity against influenza a virus. Nanomedicine (2014) 9:237-51. doi: 10.2217/nnm.13.58

162. Boisselier E, Astruc D. Gold nanoparticles in nanomedicine: preparations, imaging, diagnostics, therapies and toxicity. Chem Soc Rev. (2009) 38:1759-82. doi: 10.1039/b806051g
Conflict of Interest Statement: The authors declare that the research was conducted in the absence of any commercial or financial relationships that could be construed as a potential conflict of interest.

Copyright (c) 2019 Al-Halifa, Gauthier, Arpin, Bourgault and Archambault. This is an open-access article distributed under the terms of the Creative Commons Attribution License (CC BY). The use, distribution or reproduction in other forums is permitted, provided the original author(s) and the copyright owner(s) are credited and that the original publication in this journal is cited, in accordance with accepted academic practice. No use, distribution or reproduction is permitted which does not comply with these terms. 